\title{
Thematic networks and text types
}

\section{Shirley Carter-Thomas}

\section{(2) OpenEdition}

\author{
Journals
}

Electronic version

URL: http://journals.openedition.org/asp/2361

DOI: 10.4000/asp.2361

ISBN: 978-2-8218-0380-0

ISSN: 2108-6354

Publisher

Groupe d'étude et de recherche en anglais de spécialité

Printed version

Date of publication: 1 December 1999

Number of pages: 139-147

ISSN: 1246-8185

\section{Electronic reference}

Shirley Carter-Thomas, "Thematic networks and text types », ASp [Online], 23-26 | 1999, Online since 14 June 2011, connection on 21 December 2020. URL : http://journals.openedition.org/asp/2361 ; DOI : https://doi.org/10.4000/asp.2361

This text was automatically generated on 21 December 2020.

Tous droits réservés 


\title{
Thematic networks and text types
}

\author{
Shirley Carter-Thomas
}

1 Questions relating to text organisation can be tackled from a variety of perspectives. Approaches based on studies of schematic structure (or moves), rhetorical organisation and sentence cohesion can all provide us with insights into certain aspects of textual organisation. Another means of tackling this issue, while taking both micro and macro aspects of text organisation into account, is the study of a text's thematic structure.

In the first part of this article we will explain what exactly is to be understood by the expression thematic structure. Then, in the second part, this type of analysis will be linked to the issue of genre or text type. Are particular thematic networks specific to certain rhetorical purposes or to certain types of text? Which are the most common patterns established in specialised scientific reports, for example, as opposed to those of popularised accounts? In a third part some of the pedagogical implications linked to this line of research will be examined.

\section{Thematic structure}

3 The thematic structure of a text involves an analysis of the theme-rheme distribution (that is to say the weighting of informational blocks) at sentence level and a subsequent study of the different theme-rheme networks established across sentence boundaries. This network, referred to as thematic progression, enables us to trace the global flow of information throughout a lengthy portion of text. There are numerous theories and approaches to the study of theme and rheme. I have chosen to broadly base my analysis on the presentation of thematic structure developed by the Prague linguists in the 60s and in particular on the work of F. Danes (1974).

According to this view of thematic structure theme and rheme can be defined in a dual perspective:

$5 \quad$ 1. Theme and rheme are defined in terms of aboutness.

6 The sentential or clausal theme is what is being talked about. The rheme is what is then said about this theme 
7 2. Theme and rheme are defined in terms of the familiarity of the information they convey. The theme generally conveys information which is 'known' by the reader in that it is easily recoverable from the text or the extra-linguistic situation. The rheme on the other hand conveys information which is new or relatively unpredictable for the reader, and has not already been mentioned in the text.

The following example demonstrates what this means in practice. In the sentence below, taken from a student report, it may be assumed that what the sentence is about - the theme - is "The Iridium system". This is known or recoverable information in that "Iridium" is the global subject of the report. The subsequent information describing the system constitutes the rheme:

The Iridium system is a satellite-based, wireless personal communication network.

9 Likewise in the sentence immediately following the example quoted, the anaphoric expressions It refers back to the nominal group The Iridium system, the theme is thus already known to the reader:

It will revolutionise world-wide communications by providing a universal service.

Thematic structure is not however limited to a simple division at this local level. Once the theme/rheme structure has been analysed at sentence level it is possible to extend the networks of information structure or progressions established throughout longer sections of the text.

11 The Czech linguist F. Danes identified 3 main types of thematic progression: constant theme progression, linear progression and derived theme progression. Let us look at examples of these progressions taken from some of my students' writings.

\section{Constant theme progression}

In this type of progression the same theme or part of it appears in a series of propositions (although the wording is not necessarily identical).

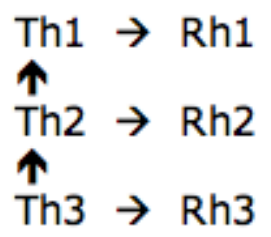

Mobile satellite systems appeared in 1976 for maritime applications and their performance is constantly improving,

\section{Linear progression}

In this type of progression the rheme or part of the rheme of one sentence becomes the theme of the next.

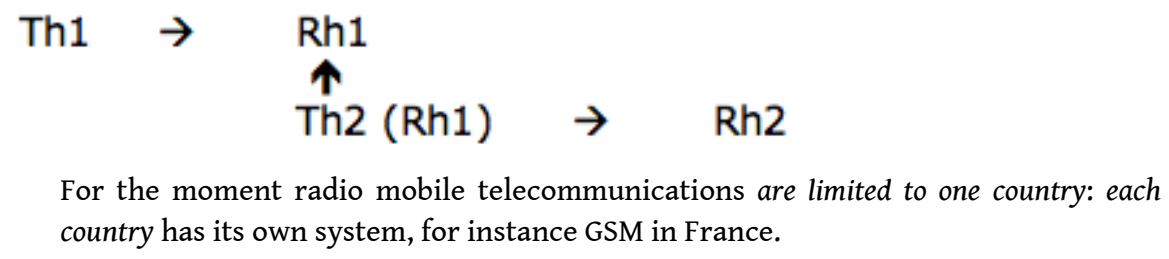




\section{Derived theme progression}

14 In the third type of thematic progression identified by Danes the themes are derived from a hyper-theme or a hyper-rheme.

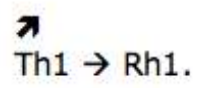

\section{T (hyper-theme)}

Th2 $\rightarrow$ Rh2

Th3 $\rightarrow$ Rh3

The different partners

Space System Loral, a branch of Loral Corporation is responsible for space segment and launching aspects.

Alcatel Espace will provide the payload modules.

Qualcomm is in charge of specifications and development of gateway and user

terminals.

15 In this example, taken from a student's report on the satellite telecommunications project Globalstar, the title of the paragraph, "The different partners", fulfils the role of hyper-theme, providing the different themes for the succeeding propositions.

These three main types of thematic progression can be interspersed and combined producing a more or less complex framework underpinning the whole text. Danes, in fact, has called thematic progression the "skeleton of the plot" (1974: 114).

17 An analysis of thematic progression enables us thus to analyse the structure of lengthy sections of text at any one time. We can identify the types of progressions most commonly found in a particular text or in a particular author's work and thus build up a picture of this aspect of text organisation.

\section{Thematic progression and text type}

18 An analysis of thematic structure can be made on any type of text. What is important is for authentic communication to take place between writer and reader. If - as is sometimes the case in language classes - the content of the students' writing is not an issue, a thematic analysis would be pointless, for thematic structure is a functional concept which relies on an active interpretative role on the part of the reader.

A thematic analysis is however ideally suited to the study of scientific texts which have a recognised organisational structure. If we take the research article, for example, it is possible to study the distribution of different types of thematic progression in the different sections of the IMRAD ${ }^{1}$ structure.

Such a study has been made by Kevin Nwogu (1990), who noticed for example, in his analysis of specialised medical texts, that there were a preponderance of constant theme progressions in the Methods and Results sections of the medical research article. In the Discussion section however there were more linear progressions. However, on the whole Nwogu noted a preference for the constant progression in the research article.

On the other hand, in popularised accounts of medical texts on very similar subjects Nwogu noted a marked preference for linear progressions. The derived theme progression was used in both the popularised and specialised articles although to a lesser degree than either of the other main types of thematic progressions. 
22 My own analysis of texts in the telecommunications field would seem to echo these results. This though is in some way expected for as Swales (1990) and many others have shown, it is not the subject matter itself but the genre which determines many aspects of textual functioning. The thematic networks established in popular scientific accounts and research articles would seem to be more constrained by such factors as purpose and intended readership.

One of the main purposes of a popular scientific article is to explain the workings of an apparatus or procedure to a non-specialist audience. The linear thematic progression is ideally suited to this, as we can see in the following extract taken from an article on optical fibre transmission speed in the New Scientist magazine:

The signal must be boosted every 40 miles or so.

त

In the past this was achieved by electronic repeaters which convert the light pulses into electronic signals, boost them and convert them back before sending them on. 區 But electronic repeaters must be pre-set to process a certain amount of information. 鸳 So increasing the information capacity of the cable would mean replacing every repeater along its length.

覧

This problem can be avoided by using optical repeaters.

櫃 These are stretches of cable that contain the light-emitting element erbium and a ' pump' laser.

䣵 The laser keeps...

In this section of his article the author is at pains to explain the benefits of amplifying the signals transmitted by optical fibres optically rather than electronically. The theme of each new sentence comes from part of the immediately preceding rheme. As a result, the explanations seem clear and easy to follow.

The frequent use of the linear progression in general science magazines also seems to be closely linked to the question of shared knowledge. The level of specialised knowledge that can be expected on the part of the reader of popularised accounts is relatively low. The author of such articles however can draw upon information already presented in preceding rhemes in order to present these elements as items of given information in a subsequent theme. In this way the stock of mutual knowledge is gradually increased. This would certainly seem to be the case in the extract just quoted.

If in the research article proper linear progressions are less frequent numerically speaking it is partly because careful explanations like the above are not usually characteristic of this genre. Argumentation or explanations of any sort are basically limited to the discussion sections of the research article. One of the main purposes of the research article is to inform other researchers of research pertaining to their domain of speciality. It is descriptive sequences therefore which are frequent, particularly in the Methods and Results sections. Let's look at another example - this time from a research article in a telecommunications related field:

Two different plastic clamps hold down the silicon vessel array...

$\uparrow$

The smaller clamp has a total contact areas of approximately $5.6 \mathrm{~mm}$

$\uparrow$ 
while the larger clamp has a contact area or approximately $18.6 \mathrm{~mm}$.

$\uparrow$

To provide an adequate clamping force, four screws with springs push down on the corners of the clamp.

\section{Pedagogical implications}

31 Having described the main types of thematic progression texts and some of their specificities with regard to scientific writing I would now like to discuss some possible pedagogical considerations.

I have analysed the thematic structure of a series of reports written in English by my French engineering students. ${ }^{2}$ First of all I identified the theme/rheme distributions at sentence level and then I attempted to follow the different thematic networks developed. When I could not easily identify a thematic structure, or establish a particular thematic pattern, I attempted to analyse the reasons for the various ruptures and breakdowns in the information flow.

33

There will always be a certain number of intentional ruptures or changes of direction within a given text. These often coincide with a change of section or paragraph. The writer can also signal the presence of an unexpected element in the theme function by means of an appropriate linking word. However, my own analysis was concerned with 
characterising the unintentional ruptures in the information flow -the points where the reader no longer understands the writer's intentions and communication breaks down.

Very often, for example, my students did not provide me (the reader) with sufficient information so as to be able to easily identify sentential themes. Consequently, following or beginning to follow a particular thematic progression is problematic. In a report dealing with a comparison between two types of satellite and their orbits students frequently did not succeed in distinguishing clearly the type of satellite in questions:

? One of the most important advantages of these orbits is the lower transmission power needed.

In this particular example which came at the beginning of a new paragraph following such a comparison it was not immediately obvious which orbit of which satellite was at stake. The use of the anaphorical expression these was not sufficiently precise.

Another problem which seemed to occur frequently involved the distribution of given and new information within the sentence. The thematic elements characteristically convey given or easily identifiable information and are generally placed before those elements conveying the rheme. I have several examples in my corpus of student productions of new information occurring before the given (already known) information. Although not necessarily leading to a complete breakdown in communication this inversion of the usual order meant that processing the information was difficult. In other words the sentence seemed awkward. In the following extract, for example:

Indeed, the higher the satellite's orbit, the more of the Earth's surface can be seen.

However, polar regions are not covered

Theme?

the presence of the nominal group polar regions as the supposed theme of the second sentence is rather sudden and as a result disconcerting. Why does the writer choose to introduce a new theme at this point, a theme which is not in fact developed in the rest of the text? In the first sentence quoted the writer establishes a link between the altitude of the satellite and the extent of its coverage. Rereading the two sentences it would seem that it is the two rhemes which are linked. The known information in the second sentence is conveyed in the verbal group covered. Our interpretation of this sentence would then have been easier if the writer had in fact nominalised this information as the theme:

However this coverage does not extend to polar regions (proposed modification)

Such a reorganisation of the theme-rheme distribution would have enabled the writer to respect the usual given-new order. The reader can then assimilate the new elements of information more easily from what would now be a linear progression.

However, modifications of this type call for a considerable amount of syntactic dexterity on the part of non-native writers. Indeed the question could be asked whether the strangeness and disorganisation encountered in my students' reports are not partly the result of their difficulties in manipulating English syntax. In other words, their language skills are not sufficient for them to organise the informational blocks of the sentence in a way which would enable the information to be processed easily.

Another reason for the awkwardness and confusion sometimes felt could however be linked to the question of reader awareness. The students' reports which constitute my corpus are supposed to be directed at a non-specialist readership. The teachers reading the reports have, in theory, a general understanding of telecommunications subjects but are not specialists in any specific field. In this respect these reports have a lot in common 
with popular journalistic type accounts. It would seem that very often the students' work does not take into account the needs of their intended reader when presenting fairly complex subject matter. When in the following extract, for example, the writer seems to confer thematic status on the nominal group 'GEO' systems the reader is once again initially puzzled:

Comparison between LEO and higher orbit systems

? An important advantage of GEO systems is the small number of satellite transmitters needed in space communication services.

41 The title of the paragraph refers to a comparison between two types of satellites, LEO satellites and higher orbit systems. The reader is first obliged to make a link for himself between the second part of the title and what he supposes to be the theme of the first sentence (GEO systems are the same as higher orbit systems) in order to interpret this sentence. This kind of link is easy to make for a specialist in satellite systems but the combination of the reversed order and the use of the synonymous expression in the title make processing this sentence difficult.

This lack of reader awareness would also seem to be reflected more generally in the types of thematic patterns created. We saw previously that in popularised accounts linear progression was prevalent. However, in my corpus of student reports constant theme progression was more widely used than linear progression:

- Constant theme progression - $45 \%$

- Linear progression - $31 \%$

- Derived theme progression - $24 \%$

While some of the constant theme progressions established did indeed seem to be suited to the descriptive functions for which they were employed, a greater use of linear progressions might have increased the clarity of the reports for a non-specialist readership.

As a conclusion I would like to emphasise what I feel to be the importance of including a study of thematic structure in text analysis. Not only does tackling text organisation from this perspective enable us to pinpoint a certain number of writing problems hard to identify through traditional error analysis, but also relating thematic structure and progression to what we already know about genre would seem potentially to be a highly useful tool.

\section{BIBLIOGRAPHY}

Danes, Frantisek. 1974. "Functional sentence perspective and the organisation of the text". In Danes, F. (ed.), Papers in Functional Sentence Perspective. Prague: Academia.

Nwogu, Kevin N. 1990. "Discourse variation in medical texts: schema, theme and cohesion in professional and journalistic accounts". Monographs in Systemic Linguistics, vol. 2, University of Nottingham. 
Nwogu, Kevin N. 1995. "Structuring scientific discourse: Using the 'given-New”'. English Teaching Forum 33/4, 22-27 <http://exchanges.state.gov/englishteaching/forum/

archives/1995/95-33-4.html>.

Swales, John M. 1990. Genre Analysis: English in Academic and Research Settings. Cambridge:

Cambridge University Press.

Thomas, Shirley. 1998. "Organisation thématique et qualité textuelle: une analyse des difficultés rencontrées par des élèves-ingénieurs francophones lorsqu'ils rédigent en anglais'. Thèse de doctorat, Université Paris V.

\section{Secondary references}

New Scientist Nº 1953, 6 November 1994.

IEEE Journal of Microelectormechanical systems vol. 7, December 1998.

New England Journal of Medicine, 21 August, 1986.

\section{NOTES}

1. Introduction, Methods, Results and Discussion.

2. See Thomas (1998).

\section{ABSTRACTS}

In this article the issue of textual organisation is analysed from the viewpoint of thematic progression. We propose to study the extent to which the different thematic networks or progressions established within a text vary depending on the type of text, namely in this instance a specialised scientific text and a popularised account. Some possible didactic offshoots from this analysis are also discussed.

Dans cet article, la question de l'organisation textuelle est abordée par l'analyse de la progression thématique. Nous nous proposons d'étudier à quel degré les différents types de progression thématique établis dans un texte sont liés à la question de son genre textuel, s'agissant en l'occurrence d'un article de recherche scientifique et d'un article de vulgarisation. Nous considérons également certaines orientations didactiques issues de cette étude.

\section{INDEX}

Mots-clés: genre textuel, progression thématique, rhème, structure thématique, thème Keywords: rheme, text type, thematic progression, thematic structure, theme 


\section{AUTHOR}

\section{SHIRLEY CARTER-THOMAS}

Shirley Carter-Thomas est enseignant-chercheur à l'Institut National des Télécommunications. Elle a soutenu en 1998, à Paris 13, une thèse intitulée « Organisation thématique et qualité textuelle : une analyse des difficultés rencontrées par des élèves ingénieurs francophones lorsqu'ils rédigent en anglais ». Elle s'intéresse à l'analyse du discours spécialisé écrit et à la linguistique fonctionnelle. shirley.thomas@it-sudparis.eu 